Research Article

\title{
The Incentive and Supervision Mechanism of Banks on Third-Party B2B Platforms in Online Supply Chain Finance Using Big Data
}

\author{
Kun Tian $\mathbb{B}$, Xintian Zhuang, and Beibei Yu \\ School of Business Administration, Northeastern University, Shenyang, Liaoning 110169, China \\ Correspondence should be addressed to Kun Tian; tiankun@st.btbu.edu.cn
}

Received 25 March 2021; Revised 12 April 2021; Accepted 29 April 2021; Published 19 May 2021

Academic Editor: Fazlullah Khan

Copyright (c) 2021 Kun Tian et al. This is an open access article distributed under the Creative Commons Attribution License, which permits unrestricted use, distribution, and reproduction in any medium, provided the original work is properly cited.

\begin{abstract}
The incentive and supervision design of cooperation between banks and B2B platforms was studied under the electronic warehouse receipt pledge financing model. Under the assumptions of B2B platform risk, neutrality, and risk aversion, a principalagent model for cooperation was established between banks and B2B platforms. Its purpose was to expand and compare the models by adding supervision variables. It also helps to analyze the effects of risk aversion coefficients on effort level, fixed payment, incentive coefficients, and the impact of bank income. This paper has analyzed the banking system's incentives and supervision mechanisms by performing numerical analysis on big data. We have used MATLAB for numerical analysis. The results show that banks' expected benefits when cooperating with risk-neutral B2B platforms are always greater than the expected benefits obtained when cooperating with risk-averse B2B platforms. But when banks act, the increase in profits exceeds the cost of regulatory measures. Besides, when the bank takes supervisory measures, the profit will be greater than the profit without supervisory measures. Hence, the B2B platform's ability to recover losses is positively correlated with the bank's expected utility. The cost coefficient of the B2B platform is negatively correlated with the bank's expected utility. The risk aversion degree does not affect the optimal effort level of the B2B platform, but it affects the optimal fixed payment and the optimal incentive coefficient.
\end{abstract}

\section{Introduction}

With the innovation of Internet finance and the rapid development of China's B2B e-commerce market, traditional supply chain financial services have also produced a new model-online supply chain finance based on third-party $\mathrm{B} 2 \mathrm{~B}$ e-commerce platforms. Its advantage is that the B2B platform can use big data analysis technology for crossvalidation, and efficiently gather and coordinate the logistics. It helps information flow and capital flow in the supply chain to achieve the rating of "subject + debt." It provides convenient financing for small, medium, and micro enterprises, and reduces the financing credit risk. But, it is undeniable that due to the asymmetry of interest and information asymmetry between the bank and the B2B platform, there is a principal-agent problem, which creates the moral hazard of hidden actions. This paper took online supply chain finance as the background. It used the electronic warehouse receipt pledge as an example to prove that it can effectively increase the bank's expected income while preventing the hidden moral hazard of the B2B platform. Some practical references are provided for financing service providers for the online supply chain finance business.

In recent years, in response to the principal-agent problem in the principal-agent relationship, scholars have established an incentive model between banks and B2B platforms to prevent the moral hazard of confidential information. However, the research on the moral hazard of hidden actions is still lacking and incomplete. Scholars such as Shi [1] and Sadlovska [2] discussed credit risk assessment of financing enterprises in online supply chain finance based on the B2B platform. Sun [3] opines that only taking incentive measures is not enough to avoid supply chain finance's moral hazard. Supervisory measures should 
be taken to prevent the moral hazard of logistics enterprises. Li [4] established a dual-channel supply chain model and pointed out that retailers' degree of risk aversion is negatively correlated with retail prices. Based on the master-slave game theory, Wang and Wang [5], Zhou [6], and others have studied the risk-averse recovery supply chain models of bank's third-party B2B platforms and obtained the bank's optimal credit line and platform maximum expected return. Steeman [7] believes that the supply chain finance business is an operating mode that effectively connects software and technology, providing cash flow for the overall development of the supply chain and strengthening cooperation between upstream and downstream enterprises in the chain. Chen [8], Aust [9], and other researchers used game theory to establish and analyze a bilateral risk-averse supply chain incentive model. The study pointed out that the supply chain system's premise to achieve coordination is that the manufacturer with the greatest risk aversion can bear the entire risk and repurchase all products. Xu and $\mathrm{Ma}$ [10] established a credit risk assessment index system for small and medium-sized enterprises in the supply chain financial environment from different aspects. These aspects are financing enterprises, core enterprises, financing project risks, the supply chain's stability where trade activities occur, and the macro environment. Summarizing the existing related research on supply chain finance, we can find that most of the literature assumes that the supply chain participants are risk-neutral. Risk-neutral is an ideal state for the convenience of research. In the research on traditional supply chain finance, some literature considers the risk aversion behavior of decision-makers and the impact of risk aversion on decision-makers' behavior. However, there is a lack of literature on supply chain coordination from risk preference in online supply chain finance research. Therefore, from the perspective of risk preference, we take the electronic warehouse receipt pledge financing based on the thirdparty $\mathrm{B} 2 \mathrm{~B}$ platform as an example and use the principalagent theory to study the bank's incentive contract thirdparty B2B platform under the model of entrusted credit. We also discuss the B2B platform's risk appetite and whether the bank takes supervisory measures on the impact of the B2B platform's optimal effort level, the bank's optimal fixed payment, the bank's optimal incentive coefficient, and the bank's optimal expected return. The paper also considers the third-party B2B's ability to recover losses, the cost coefficient, the degree of risk aversion, the bank's supervision on the bank's optimal expected return under different assumptions, and the moral hazard prevention strategy in the new model.

\section{The Bank's Incentive and Supervision of the Risk-Neutral Third-Party B2B Platform}

This section discusses the problem description, assumption, parameter setting, model construction, and analysis on the risk-neutral third-party B2B platform.
2.1. Problem Description. Online supply chain financial credit models based on banks and third-party B2B platforms can be divided into three models: joint credit, individual credit, and entrusted credit. After practice, the entrusted credit model has become the main cooperation method between banks and third-party B2B platforms. So, this paper introduces the entrusted credit model. Under the entrusted credit method, the third-party $\mathrm{B} 2 \mathrm{~B}$ platform accepts the bank's entrustment. It uses the electronic credit information, logistics, supply chain information, capital flow information, and other behavioral data information of the financing enterprise. It holds to independently extend credit to the financing enterprise and issues an evaluation report and gets a certain income. However, in the process of entrusted credit, the bank cannot see the process of the third-party B2B platform's efforts because of the information asymmetry. These are still the results of hard work, so there will still be principal-agent problems, and third-party B2B platforms may choose a lower level of effort to obtain greater benefits. Therefore, to ensure that their interests are not lost, banks need to formulate incentive contracts to maximize their interests. Based on the previous research on the principalagent relationship and the description of the supply chain finance business, this paper, taking electronic warehouse receipt financing as an example, designs the incentive contract between banks and the third-party B2B platforms.

\subsection{Basic Assumptions}

Hypothesis 1. This section first discusses the situation when banks cooperate with risk-neutral third-party B2B platforms. It is assumed that banks and third-party B2B platforms are both risk-neutral.

Hypothesis 2. The time value of money is not considered for the time being. It is assumed that banks and third-party B2B platforms are rational decision-makers and aim to maximize their interests.

Hypothesis 3. In the principal-agent relationship, banks and third-party B2B platforms have asymmetric information, and banks cannot know the true degree of effort of the thirdparty logistics platforms. As a result, it has to make an evaluation based on the results of the effort.

\subsection{Parameter Setting. Suppose that Bank $Z$ conducts} electronic warehouse receipt financing business on a thirdparty B2B platform within a certain period, and the total credit limit is $Q$. During this period, many financing companies on the $\mathrm{B} 2 \mathrm{~B}$ platform experience a temporary shortage of funds, and they file electronic warehouse receipt financing applications with the bank. Assuming that enough companies have submitted financing applications, the financing needs are far greater than the total credit limit.

The third-party B2B platform's efforts and capabilities are private information that other parties cannot obtain and can only be evaluated based on their efforts. Suppose the 
third-party B2B platform's effort level is $A_{E}$ a one-dimensional continuous variable between $[0,1]$, and the output function of the third-party $\mathrm{B} 2 \mathrm{~B}$ platform is $W=-a A_{E}+b+d+\varepsilon,(W \geq 0)$.

In the equation, the variable $W$ can be understood as the amount of loss formed during the loan cycle. The variable $a$ represents the ability of the third-party $\mathrm{B} 2 \mathrm{~B}$ platform to recover losses. It is embodied in information-processing technology, operational expertise, the perfection of approval procedures, and personnel specialization. The Stronger the ability is, the more losses can be recovered under the same level of effort. Similarly, under the same level of ability, the harder you work, the more losses can be recovered, that is, $W^{\prime} \leq 0$. Variable $b$ refers to the amount of loss caused by the type of financing enterprise, and the financing enterprises with different credits generate different amounts of loan losses. Variable $d$ represents the amount of loan business losses incurred by the laziness, inaction, and inactivity of third-party B2B platforms, such as imperfect approval procedures, unsatisfactory staff, operating errors, etc. The variable $\varepsilon$ is the sum of various uncertain factors such as the impact of the market environment on the output function and the third-party B2B platform's efforts $\varepsilon_{\sim} N\left(0, \sigma^{2}\right)$.

The B2B platform follows the financing applications' sequence and conducts credit reviews on financing companies' electronic credit information. Financing companies that meet the scoring or rating requirements are eligible for loans, and the bank's total credit line $Q$ within this period will stop credit.
For the convenience of analysis, suppose that the bank loan interest rate is simple interest. All enterprises pay the interest in one lump sum at maturity. The bank loan interest rate is $r$, the loan period is $T$, then the bank loan income is: $R_{B}=Q r T$.

Assume that the bank's payment to the third-party $\mathrm{B} 2 \mathrm{~B}$ platform is $S_{E}=F+\alpha\left(W(0)-W\left(A_{E}\right)\right)$, the variable $F$ is the bank's fixed payment to the third-party B2B platform, and $\alpha$ is the bank's incentive coefficient to the third-party B2B platform. This income distribution mechanism is called the "sharing system." The third-party B2B platform's remuneration is directly related to the output, but the risk of output fluctuations is shared between the bank and the third-party B2B platform.

According to the basic principles of microeconomics, it is assumed that the effort cost function of the third-party B2B platform follows the secondary expression of effort level, i.e., $C_{E}=\beta A_{E}^{2} / 2 . \beta$ is the cost coefficient, namely, the effectiveness of the third-party B2B platform's effort on loan success. It is related to the capability of the platform of the third-party $\mathrm{B} 2 \mathrm{~B}$. The smaller the value of $\beta$, the stronger the third-party B2B platform's capability and the higher the effectiveness.

2.4. Model Construction and Analysis. The expected income of the bank can be obtained through the above analysis:

$$
\begin{aligned}
U & =R_{B}-W-S_{E}=Q r T-\left(-a A_{E}+b+d+\varepsilon\right)-\left[F+\alpha\left(W(0)-W\left(A_{E}\right)\right)\right] \\
& =Q r T+(1-\alpha) a A_{E}-F-b-d-\varepsilon .
\end{aligned}
$$

Because the bank is risk-neutral, its expected utility is equal to its expected return:

$$
E(U)=Q r T+(1-\alpha) a A_{E}-F-b-d .
$$

The actual currency income of the third-party B2B platform is

$$
\omega=S_{E}-C_{E}=F+\alpha a A_{E}-\frac{\beta A_{E}^{2}}{2} .
$$

Because the third-party platform B2B is risk-neutral, the absolute risk aversion measure $\rho=0$ at this time, and the equivalent certainty income is

$$
E(\omega)-\frac{1}{2} \rho \operatorname{Var}(\omega)=F+\alpha a A_{E}-\frac{\beta A_{E}^{2}}{2} .
$$

Since the expected utility of the third-party B2B platform is equivalent to its deterministic equivalent income, the expected utility of the third-party $\mathrm{B} 2 \mathrm{~B}$ platform is

$$
V=E(\omega)-\frac{1}{2} \rho \operatorname{Var}(\omega)=F+\alpha a A_{E}-\frac{\beta A_{E}^{2}}{2} .
$$

As a rational decision-maker, the necessary condition for a third-party $\mathrm{B} 2 \mathrm{~B}$ platform to participate in financing business is to obtain a higher utility than its retained utility $V^{0}$; otherwise, it will give up participating in the search for other opportunities. Therefore, third-party B2B platforms need to meet participation constraints:

$$
V=F+\alpha a A_{E}-\frac{\beta A_{E}^{2}}{2} \geq V^{0} .
$$

If $V<V^{0}$, the third-party B2B platform's monetary income was less than the average level and the participation constraints were not met. Then, the third-party B2B platform would not accept the bank's entrustment. If $V \geq V^{0}$, the third-party B2B platform's monetary income was equal to or higher than the average level and the participation constraints were met. Then, the third-party B2B platform will accept the bank's entrustment.

In the principal-agent relationship, due to information asymmetry, the bank cannot observe the third-party B2B platform's effort. A rational third-party B2B platform will use its information advantages to select the best level of effort $A_{E}$ to maximize its interests, thus harming the interest of the 
bank. Therefore, third-party B2B platforms must also meet incentive compatibility constraints:

$$
A_{E} \in \arg \max V=E(\omega)-\frac{1}{2} \rho \operatorname{Var}(\omega),
$$

which is

$$
A_{E} \in \arg \max \left(F+\alpha a A_{E}-\frac{\beta A_{E}^{2}}{2}\right) .
$$

Find the first derivative of the effort level for the incentive compatibility $A_{E}$ constraint:

$$
\begin{aligned}
\alpha a-\beta A_{E} & =0, \\
A_{E}^{* *} & =\frac{a \alpha}{\beta} .
\end{aligned}
$$

Proposition 1. In bank supply chain finance based on a risk-neutral third-party $B 2 B$ platform, during the credit review process of the $B 2 B$ platform, its optimal level of effort is positively correlated with the incentive coefficient $\alpha$ and the $B 2 B$ platform's ability to recover losses $a$, and has a positive relationship with the cost coefficient $\beta$ of the $B 2 B$ platform.

Proof. From equation (10), $\partial A_{E}^{* *} / \partial \alpha=a / \beta>0$, $\partial A_{E}^{* *} / \partial a=\alpha / \beta>0$, and $\partial A_{E}^{* *} / \partial \beta=-\alpha / \beta^{2}<0$, so the optimal effort level increases with the increase of the incentive coefficient $\alpha$ provided by the bank and increases with the increase of the B2B platform's ability to recover losses a and decreases as the cost factor $\beta$ of $\mathrm{B} 2 \mathrm{~B}$ platform increases, and the proof is complete.

When banks cooperate with risk-neutral third-party B2B platforms, they maximize the bank's utility and establish a principal-agent model while meeting the participation constraints (IC) and incentive constraints (IR) of the thirdparty $\mathrm{B} 2 \mathrm{~B}$ platform:

$$
\begin{aligned}
& \max _{\alpha, F, A_{E}} E(U)=Q r T+(1-\alpha) a A_{E}-F-b-d, \\
& \text { s.t. (IC): } V \geq V^{0}, \\
& \text { (IR): } A_{E} \in \arg \max V .
\end{aligned}
$$

In the best case, the third-party B2B platform's utility is equal to its retained utility:

$$
V=F+\alpha a A_{E}-\frac{\beta A_{E}^{2}}{2}=V^{0} .
$$

Substituting equation (10) into (12) indicates that banks cooperate with risk-neutral third-party B2B platforms, and the fixed payment to third-party B2B platforms without supervision measures is

$$
F_{1}=V^{0}-\frac{a^{2} \alpha^{2}}{2 \beta} .
$$

Substituting equations (10) and (13) into (11), we can get

$$
E(U)=Q r T+\frac{a^{2} \alpha}{\beta}-\frac{a^{2} \alpha^{2}}{2 \beta}-V^{0}-b-d .
$$

The first derivative of the excitation coefficient $\alpha$ for $E(U)$ can be obtained:

$$
\begin{aligned}
\frac{a^{2}}{\beta}-\frac{a^{2} \alpha}{\beta} & =0, \\
\alpha^{* *} & =1 .
\end{aligned}
$$

Substituting equation (16) into (13), we can obtain

$$
F^{* *}=V^{0}-\frac{a^{2}}{2 \beta}
$$

Substituting equations (10), (16), and (17) into the objective function indicates that when the bank cooperates with a risk-neutral third-party B2B platform, the optimal return of the bank is

$$
E(U)^{* *}=Q r T+\frac{a^{2}}{2 \beta}-V^{0}-b-d .
$$

\section{Research on Incentives under Supervision Measures Taken by Banks}

This section discusses the problem description, assumption, parameter setting, and model construction and analysis on the risk-neutral third-party $\mathrm{B} 2 \mathrm{~B}$ platform.

3.1. Problem Description. The problem of information asymmetry arising in entrusted credit can also be overcome through supervision measures. It is assumed that banks take supervision measures on third-party B2B platforms to encourage them to work harder and reduce loan losses. The focus of bank supervision is whether the third-party $\mathrm{B} 2 \mathrm{~B}$ platform works hard and the credit capability of the $\mathrm{B} 2 \mathrm{~B}$ platform. The supervision of credit capacity can include improving data processing technology, the perfection of review procedures, and staff's regular training. Such supervision will enhance third-party B2B platforms' credit review capacity and make up for more loan losses.

3.2. Parameter Setting. Based on the previous analysis and the parameter variables that have been set above, this section also introduces the parameters when banks take supervisory measures. At this time, the third-party $\mathrm{B} 2 \mathrm{~B}$ platform's output function is expressed as $W=-(a+\lambda(\theta)) A_{E}+b+$ $d+\varepsilon(W \geq 0)$, where the variable $\theta$ is the bank's supervision strength and $\lambda(\theta)$ represents the output coefficient of the third-party B2B platform. $\lambda(\theta)=\theta^{2}$ is assumed, so $\lambda(\theta)$ changes follow the law of diminishing marginal returns, that is, $\lambda^{\prime}(\theta) \geq 0, \lambda^{\prime \prime}(\theta) \leq 0$. The cost $C_{B}(\theta)$ incurred by banks due to supervision is supposedly $C_{B}(\theta)=\theta^{2} / 16$, meeting $C_{B}^{\prime}(\theta) \geq 0 C_{B}^{\prime \prime}(\theta) \geq 0$. 
3.3. Model Construction and Analysis. From the above assumptions and analysis, we can see that the bank's income, when the bank takes supervisory measures, is

$$
\begin{aligned}
U^{\prime} & =R_{B}-W-S_{E}-C_{B}(\theta) \\
& =Q r T-\left[-(a+\lambda(\theta)) A_{E}+b+d+\varepsilon\right]-\left[F+\alpha\left(W(0)-W\left(A_{E}\right)\right)\right]-C_{B}(\theta) \\
& =Q r T+(1-\alpha)(a+\lambda(\theta)) A_{E}-F-b-d-C_{B}(\theta)-\varepsilon .
\end{aligned}
$$

Because banks are risk-neutral, their expected utility is equal to the expected return:

$$
E\left(U^{\prime}\right)=Q r T+(1-\alpha)\left(a+\theta^{1 / 2}\right) A_{E}-F-b-d-\frac{1}{16} \theta^{2} .
$$

Under the supervision measures taken by the bank, the actual currency income of the third-party B2B platform is

$$
\omega^{\prime}=S_{E}-C_{E}=F+\alpha(a+\lambda(\theta)) A_{E}-\frac{\beta A_{E}^{2}}{2} .
$$

Because the third-party platform B2B is risk-neutral, the absolute risk aversion measure $\rho=0$ at this time, the equivalent certainty income, is

$$
E\left(\omega^{\prime}\right)-\frac{1}{2} \rho \operatorname{Var}\left(\omega^{\prime}\right)=F+\alpha(a+\lambda(\theta)) A_{E}-\frac{\beta A_{E}^{2}}{2}
$$

Since the expected utility of the third-party B2B platform is equivalent to its deterministic equivalent income, the expected utility of the third-party B2B platform is

$$
V^{\prime}=E\left(\omega^{\prime}\right)-\frac{1}{2} \rho \operatorname{Var}\left(\omega^{\prime}\right)=F+\alpha\left(a+\theta^{1 / 2}\right) A_{E}-\frac{\beta A_{E}^{2}}{2} .
$$

As a rational decision-maker, the necessary condition for a third-party B2B platform to participate in financing business is to obtain a higher utility than its retained utility $V^{0}$; otherwise, it will give up participating in the search for other opportunities. Therefore, third-party B2B platforms need to meet participation constraints:

$$
V^{\prime}=F+\alpha\left(a+\theta^{1 / 2}\right) A_{E}-\frac{\beta A_{E}^{2}}{2} \geq V^{0} .
$$

If $V^{\prime}<V^{0}$, the third-party B2B platform's monetary income was less than the average level and the participation constraints were not met. Then, the third-party B2B platform would not accept the bank's entrustment. If $V^{\prime} \geq V^{0}$, the third-party B2B platform's monetary income was equal to or higher than the average level, and the participation constraints were met. Then, the third-party B2B platform will accept the bank's entrustment.

In the principal-agent relationship, the bank cannot observe the level of effort of the third-party B2B platform due to information asymmetry. A rational third-party B2B platform will use its information advantages to select the best level of effort $A_{E}$ to maximize its interests, thus harming the interest of the bank. Therefore, third-party B2B platforms must also meet incentive compatibility constraints:

$$
A_{E} \in \arg \max V^{\prime}=E\left(\omega^{\prime}\right)-\frac{1}{2} \rho \operatorname{Var}\left(\omega^{\prime}\right), \quad V^{\prime} \geq V^{0} .
$$

That is,

$$
A_{E} \in \arg \max \left(F+\alpha\left(a+\theta^{1 / 2}\right) A_{E}-\frac{\beta A_{E}^{2}}{2}\right) .
$$

Finding the level of effort for the incentive compatibility $A_{E}$ constraint and the first derivative can obtain

$$
\begin{aligned}
\alpha\left(a+\theta^{1 / 2}\right)-\beta A_{E} & =0, \\
\widehat{A}_{E}^{* *} & =\frac{\left(a+\theta^{1 / 2}\right) \alpha}{\beta} .
\end{aligned}
$$

Proposition 2. In the bank's supply chain finance based on a risk-neutral third-party B2B platform, when the bank takes supervisory measures, during the credit review process, the best effort level of the B2B platform is positively correlated with the bank's supervision $\theta$, the bank's incentive coefficient $\alpha$ for the B2B platform, and the B2B platform's ability a to recover losses, and it is negatively correlated with the $B 2 B$ platform cost coefficient $\beta$.

Proof. From equation (28), we can get $\partial \widehat{A}_{E^{* *}}^{* *} / \partial \alpha=a+\lambda(\theta) / \beta>0, \quad \partial \widehat{A}_{E}^{* *} / \partial a=\alpha / \beta>0$, $\partial \widehat{A}_{E}^{* *} / \partial \theta=\alpha / \beta 1 / 2 \theta^{1 / 2}>0, \partial \widehat{A}_{E}^{* *} / \partial \beta=-\alpha / \beta^{2}<0$, so the optimal effort level increases with the increase of supervision intensity $\theta$, increases with the increase of ability $a$, and increases with the increase of incentive coefficient $\alpha$, and decreases with the increase of the cost coefficient $\beta$. The proof is complete.

Under the supervision measures taken by the bank on the third-party B2B platform, it also meets the participation constraints (IC) and incentive constraints (IR) of the thirdparty B2B platform to maximize the bank's utility and establish a principal-agent model: 


$$
\begin{aligned}
& \max _{\alpha, F, A_{E}} E\left(U^{\prime}\right)=Q r T+(1-\alpha)(a+\lambda(\theta)) A_{E}-F-b-d-C_{B}(\theta), \\
& \text { s.t. (IC): } V^{\prime} \geq V^{0}, \\
& \quad \text { (IR): } A_{E} \in \arg \max V^{\prime} .
\end{aligned}
$$

In the best case, the third-party B2B platform's utility is equal to its retained utility:

$$
V^{\prime}=F+\alpha\left(a+\theta^{1 / 2}\right) A_{E}-\frac{\beta A_{E}^{2}}{2}=V^{0} .
$$

Substituting equation (28) into equation (30) gives that when banks cooperate with risk-neutral third-party B2B platforms, the fixed payment given to third-party B2B platforms under supervision measures is

$$
e F_{2}=V^{0}-\frac{\left(a+\theta^{1 / 2}\right)^{2} \alpha^{2}}{2 \beta}
$$

Substituting equations (28) and (31) into (29), we can get $E(U)=Q r T+\frac{\left(a+\theta^{1 / 2}\right)^{2} \alpha}{\beta}-\frac{\left(a+\theta^{1 / 2}\right)^{2} \alpha^{2}}{2 \beta}-V^{0}-b-d-\frac{1}{16} \theta^{2}$.

Find the first derivative of the excitation coefficient $\alpha$ for $E(U)$ to get

$$
\begin{gathered}
\frac{\left(a+\theta^{1 / 2}\right)^{2}}{\beta}-\frac{\left(a+\theta^{1 / 2}\right)^{2} \alpha}{\beta}=0, \\
\widehat{\alpha}^{* *}=1 .
\end{gathered}
$$

Substituting equation (34) into (31), we can obtain

$$
\widehat{F}^{* *}=V^{0}-\frac{\left(a+\theta^{1 / 2}\right)^{2}}{2 \beta}
$$

Substituting equations (28), (34), and (35) into the objective function, it yields that when the bank cooperates with a risk-neutral third-party B2B platform, and the bank takes supervisory measures, the optimal return of the bank is

$$
E\left(U^{\prime}\right)^{* *}=Q r T+\frac{\left(a+\theta^{1 / 2}\right)^{2}}{2 \beta}-V^{0}-b-d-\frac{1}{16} \theta^{2} .
$$

\section{Banks' Incentives for Risk-Aversion Third- Party B2B Platforms}

This section discusses the problem description, assumption, parameter setting, model construction, and analysis on the risk-neutral third-party $\mathrm{B} 2 \mathrm{~B}$ platform.
4.1. Problem Description. This section analyzes the bank's research on the third-party B2B platform's incentive contract when the bank cooperates with the risk-averse thirdparty B2B platform. The results are compared with and without considering the bank's supervisory measures and the optimal level of effort of the third-party B2B platform. The incentive coefficient and fixed payment that the bank gives to the third-party $\mathrm{B} 2 \mathrm{~B}$ platform and the expected utility of the bank have an impact on the bank's utility function. The parameter variables set in the previous section are used in this part.

4.2. Basic Assumptions. In addition to the rational person assumption and information asymmetry assumption made in the previous section, the following assumptions will also be made:

Banks are risk-neutral, and the risk attitude of the thirdparty B2B platform is risk aversion. The third-party B2B platform has constant risk aversion characteristics, i.e., $V=V_{0}-e^{-\rho \omega}$, the constant absolute risk aversion measure, the actual currency income, and a normal value, the reserved utility of which is $V^{0}$.

\subsection{Model Construction and Analysis}

4.3.1. Monitoring Measures Not Being Considered. The expected income of the bank can be obtained through the above analysis:

$$
\begin{aligned}
U & =R_{B}-W-S_{E} \\
& =Q r T-\left(-a A_{E}+b+d+\varepsilon\right)-\left[F+\alpha\left(W(0)-W\left(A_{E}\right)\right)\right] \\
& =Q r T+(1-\alpha) a A_{E}-F-b-d-\varepsilon .
\end{aligned}
$$

Because the bank is risk-neutral, its expected utility is equal to its expected return:

$$
E(U)=Q r T+(1-\alpha) a A_{E}-F-b-d .
$$

The actual currency income of the third-party B2B platform is

$$
\omega=S_{E}-C_{E}=F+\alpha a A_{E}-\frac{\beta A_{E}^{2}}{2} .
$$

Because the third-party platform B2B is a risk-aversion type, its certainty equivalent income is 


$$
E(\omega)-\frac{1}{2} \rho \operatorname{Var}(\omega)=F+\alpha a A_{E}-\frac{\beta A_{E}^{2}}{2}-\frac{1}{2} \rho \alpha^{2} \sigma^{2} .
$$

Since the expected utility of the third-party B2B platform is equivalent to its deterministic equivalent income, the expected utility of the third-party B2B platform is

$$
V=E(\omega)-\frac{1}{2} \rho \operatorname{Var}(\omega)=F+\alpha a A_{E}-\frac{\beta A_{E}^{2}}{2}-\frac{1}{2} \rho \alpha^{2} \sigma^{2} .
$$

As a rational decision-maker, the necessary condition for a third-party B2B platform to participate in financing business is to obtain a higher utility than its retained utility $V^{0}$; otherwise, it will give up participating in the search for other opportunities. Therefore, third-party B2B platforms need to meet participation constraints:

$$
V=F+\alpha a A_{E}-\frac{\beta A_{E}^{2}}{2}-\frac{1}{2} \rho \alpha^{2} \sigma^{2} \geq V^{0} .
$$

If $V^{\prime}<V^{0}$, the third-party B2B platform's monetary income was less than the average level and the participation constraints were not met. Then, the third-party B2B platform would not accept the bank's entrustment. If $V^{\prime} \geq V^{0}$, the third-party B2B platform's monetary income was equal to or higher than the average level, and the participation constraints were met. Then, the third-party B2B platform will accept the bank's entrustment.

In the principal-agent relationship, due to information asymmetry, the bank cannot observe the level of effort of the third-party B2B platform, and a rational third-party B2B platform will use its information advantages to select the best level of effort $A_{E}$ to maximize its interests, thus harming the interest of the bank. Therefore, third-party B2B platforms must also meet incentive compatibility constraints:

$$
A_{E} \in \arg \max V=E(\omega)-\frac{1}{2} \rho \operatorname{Var}(\omega),
$$

which is

$$
A_{E} \in \arg \max \left(F+\alpha a A_{E}-\frac{\beta A_{E}^{2}}{2}-\frac{1}{2} \rho \alpha^{2} \sigma^{2}\right) .
$$

The first derivative of the effort level $A_{E}$ for the incentive compatibility constraint can be obtained:

$$
\begin{aligned}
\alpha a-\beta A_{E} & =0, \\
A_{E}^{*} & =\frac{a \alpha}{\beta} .
\end{aligned}
$$

Proposition 3. In the bank's supply chain finance based on the risk-averse third-party $B 2 B$ platform, during the credit review process of the $B 2 B$ platform, its optimal effort level is positively correlated with the incentive coefficient $\alpha$ and the $B 2 B$ platform's ability to recover losses $a$, and there is a negative correlation with the cost coefficient $\beta$ of the $B 2 B$ platform.
Proof. From equation (46), $\partial A_{E}^{*} / \partial \alpha=a / \beta>0$, $\partial A_{E}^{*} / \partial a=\alpha / \beta>0, \partial A_{E}^{*} / \partial \beta=-\alpha / \beta^{2}<0$, so the effort level increases with the increase of the incentive coefficient $\alpha$, increases with the increase of the ability $a$, and decreases with the increase of the cost coefficient $\beta$. The proof is complete.

Under entrusted credit, the third-party B2B platform's efforts determine the success of the loan business. Due to information asymmetry, the third-party B2B platform may not work hard. Therefore, a proxy-agent model is established to analyze the bank's incentive mechanism for the third-party $\mathrm{B} 2 \mathrm{~B}$ platform. That is, to maximize the bank's utility under the conditions of meeting the participation constraints (IC) and incentive constraints (IR) of the third-party $\mathrm{B} 2 \mathrm{~B}$ platform, the principal-agent model is

$$
\begin{aligned}
& \max _{\alpha, F, A_{E}} E(U)=\operatorname{Qr} T+(1-\alpha) a A_{E}-F-b-d, \\
& \text { s.t. (IC): } V \geq V^{0}, \\
& \text { (IR): } A_{E} \in \arg \max V .
\end{aligned}
$$

In the best case, the third-party B2B platform's utility is equal to its retained utility:

$$
V=F+\alpha a A_{E}-\frac{\beta A_{E}^{2}}{2}-\frac{1}{2} \rho \alpha^{2} \sigma^{2}=V^{0} .
$$

Substituting equation (46) into (48) indicates that banks cooperate with risk-averse third-party B2B platforms, and the fixed payment to third-party B2B platforms without supervision measures is

$$
F_{3}=V^{0}-\frac{a^{2} \alpha^{2}}{2 \beta}+\frac{1}{2} \rho \alpha^{2} \sigma^{2} .
$$

Substituting equations (46) and (49) into (47), we can get

$$
E(U)=Q r T+\frac{a^{2} \alpha}{\beta}-\frac{a^{2} \alpha^{2}}{2 \beta}-V^{0}-\frac{1}{2} \rho \alpha^{2} \sigma^{2}-b-d .
$$

For the first derivative of the excitation coefficient, $\alpha$ can be obtained

$$
\begin{aligned}
\frac{a^{2}}{\beta}-\frac{a^{2} \alpha}{\beta}-\rho \alpha^{2} \sigma^{2} & =0, \\
\alpha^{*} & =\frac{a^{2}}{a^{2}+\beta \rho \sigma^{2}} .
\end{aligned}
$$

Substituting equation (52) into (49), we can obtain,

$$
F^{*}=V^{0}+\frac{\beta \rho \sigma^{2} a^{4}-a^{6}}{2 \beta\left(a^{2}+\beta \rho \sigma^{2}\right)} .
$$

Substituting equations (46), (52), and (53) into the objective function, when the bank cooperates with a riskaverse third-party B2B platform, without taking supervision measures, the bank's optimal profit is: 


$$
E(U)^{*}=Q r T+\frac{a^{4}}{2 \beta\left(a^{2}+\beta \rho \sigma^{2}\right)}-V^{0}-b-d
$$

4.3.2. Monitoring Measures Being Considered. From the above assumptions and analysis, we can observe that under the bank's supervisory measures, the bank's income is

$$
\begin{aligned}
U^{\prime} & =R_{B}-W-S_{E}-C_{B}(\theta) \\
& =Q r T-\left[-(a+\lambda(\theta)) A_{E}+b+d+\varepsilon\right]-\left[F+\alpha\left(W(0)-W\left(A_{E}\right)\right)\right]-C_{B}(\theta) \\
& =Q r T+(1-\alpha)(a+\lambda(\theta)) A_{E}-F-b-d-C_{B}(\theta)-\varepsilon .
\end{aligned}
$$

Because banks are risk-neutral, their expected utility is equal to the expected return

$$
E\left(U^{\prime}\right)=Q r T+(1-\alpha)\left(a+\theta^{1 / 2}\right) A_{E}-F-b-d-\frac{1}{16} \theta^{2} .
$$

Under the supervision measures taken by the bank, the actual currency income of the third-party B2B platform is

$$
\omega^{\prime}=S_{E}-C_{E}=F+\alpha(a+\lambda(\theta)) A_{E}-\frac{\beta A_{E}^{2}}{2} .
$$

Because the third-party platform B2B is risk-aversion, its certainty equivalent income is

$E\left(\omega^{\prime}\right)-\frac{1}{2} \rho \operatorname{Var}\left(\omega^{\prime}\right)=F+\alpha(a+\lambda(\theta)) A_{E}-\frac{\beta A_{E}^{2}}{2}-\frac{1}{2} \rho \alpha^{2} \sigma^{2}$.

Since the expected utility of the third-party B2B platform is equivalent to its deterministic equivalent income, the expected utility of the third-party B2B platform is

$$
V^{\prime}=E\left(\omega^{\prime}\right)-\frac{1}{2} \rho \operatorname{Var}\left(\omega^{\prime}\right)=F+\alpha\left(a+\theta^{1 / 2}\right) A_{E}-\frac{\beta A_{E}^{2}}{2}-\frac{1}{2} \rho \alpha^{2} \sigma^{2} .
$$

As a rational decision-maker, the necessary condition for a third-party $\mathrm{B} 2 \mathrm{~B}$ platform to participate in financing business is to obtain a higher utility than its retained utility $V^{0}$; otherwise, it will give up participating in the search for other opportunities. Therefore, third-party B2B platforms need to meet participation constraints:

$$
V^{\prime}=F+\alpha\left(a+\theta^{1 / 2}\right) A_{E}-\frac{\beta A_{E}^{2}}{2}-\frac{1}{2} \rho \alpha^{2} \sigma^{2} \geq V^{0} .
$$

If $V^{\prime}<V^{0}$, the third-party B2B platform's monetary income was less than the average level, and the participation constraints were not met. Then, the third-party B2B platform would not accept the bank's entrustment. If $V^{\prime} \geq V^{0}$, the third-party B2B platform's monetary income was equal to or higher than the average level, and the participation constraints were met. Then, the third-party B2B platform will accept the bank's entrustment.

In the principal-agent relationship, due to information asymmetry, the bank cannot observe the third-party B2B platform's effort. A rational third-party B2B platform will use its information advantages to select the best level $A_{E}$ of effort to maximize its interests, thus harming the interest of the bank. Therefore, third-party B2B platforms must also meet incentive compatibility constraints:

$$
A_{E} \in \arg \max V^{\prime}=E\left(\omega^{\prime}\right)-\frac{1}{2} \rho \operatorname{Var}\left(\omega^{\prime}\right) .
$$

That is,

$$
A_{E} \in \arg \max \left(F+\alpha\left(a+\theta^{1 / 2}\right) A_{E}-\frac{\beta A_{E}^{2}}{2}-\frac{1}{2} \rho \alpha^{2} \sigma^{2}\right) .
$$

The first derivative of the effort level $A_{E}$ for the incentive compatibility constraint can be obtained:

$$
\begin{aligned}
\alpha\left(a+\theta^{1 / 2}\right)-\beta A_{E} & =0, \\
\widehat{A}_{E}^{*} & =\frac{\left(a+\theta^{1 / 2}\right) \alpha}{\beta} .
\end{aligned}
$$

Proposition 4. In the bank's supply chain finance based on a risk-averse third-party $B 2 B$ platform, when the bank takes supervisory measures, there is a positive correlation between the optimal effort level and the incentive coefficient $\alpha$, the B2B platform's ability to recover losses $a$, and the intensity of bank supervision $\theta$, but there is a negative correlation with the cost coefficient $\beta$ of the $B 2 B$ platform during the credit review process.

Proof. From equation (64), we can get $\partial \widehat{A}_{E}^{*} / \partial \alpha=a+$ $\theta^{1 / 2} / \beta>0, \quad \partial \widehat{A}_{E}^{*} / \partial a=\alpha / \beta>0, \quad \partial \widehat{A}_{E}^{*} / \partial \theta=\alpha / \beta 1 / 2 \theta^{1 / 2}>0$, $\partial \widehat{A}_{E}^{*} / \partial \beta=-\alpha / \beta^{2}<0$, so the optimal effort level increases with the increase of incentive coefficient $\alpha$, increases with the increase of ability $a$, and increases with the increase of bank supervision $\theta$, and decreases with the increase of the cost coefficient $\beta$. The proof is complete.

Under the supervision measures taken by the bank on the third-party B2B platform, it also meets the participation constraints (IC) and incentive constraints (IR) of the thirdparty B2B platform to maximize the bank's utility and establish a principal-agent model: 


$$
\begin{aligned}
& \max _{\alpha, F, A_{E}} E\left(U^{\prime}\right)=Q r T+(1-\alpha)(a+\lambda(\theta)) A_{E}-F-b-d-\frac{1}{16} \theta^{2}, \\
& \text { s.t. (IC): } V^{\prime} \geq V^{0}, \\
& \text { (IR): } A_{E} \in \arg \max V^{\prime} .
\end{aligned}
$$

In the best case, the third-party B2B platform's utility is equal to its retained utility:

$$
V^{\prime}=F+\alpha\left(a+\theta^{1 / 2}\right) A_{E}-\frac{\beta A_{E}^{2}}{2}-\frac{1}{2} \rho \alpha^{2} \sigma^{2}=V^{0} .
$$

Substituting equation (58) into (60) indicates that when banks cooperate with risk-averse third-party B2B platforms, the fixed payment to third-party B2B platforms under supervision measures is

$$
F_{4}=V^{0}-\frac{\left(a+\theta^{1 / 2}\right)^{2} \alpha^{2}}{2 \beta}+\frac{1}{2} \rho \alpha^{2} \sigma^{2}
$$

Substituting equations (64) and (67) into (65), we can get

$$
E(U)=Q r T+\frac{\left(a+\theta^{1 / 2}\right)^{2} \alpha}{\beta}-\frac{\left(a+\theta^{1 / 2}\right)^{2} \alpha^{2}}{2 \beta}-V^{0}-\frac{1}{2} \rho \alpha^{2} \sigma^{2}-b-d-\frac{1}{16} \theta^{2}
$$

Find the first derivative of the excitation coefficient $\alpha$ of $E(U)$ to get

$$
\begin{aligned}
\frac{\left(a+\theta^{1 / 2}\right)^{2}}{\beta}-\frac{\left(a+\theta^{1 / 2}\right)^{2} \alpha}{\beta}-\rho \alpha \sigma^{2} & =0, \\
\widehat{\alpha}^{*} & =\frac{\left(a+\theta^{1 / 2}\right)^{2}}{\left(a+\theta^{1 / 2}\right)^{2}+\beta \rho \sigma^{2}} .
\end{aligned}
$$

Substituting equation (70) into (67), we can obtain,

$$
\widehat{F}^{*}=V^{0}+\frac{\beta \rho \sigma^{2}\left(a+\theta^{1 / 2}\right)^{4}-\left(a+\theta^{1 / 2}\right)^{6}}{2 \beta\left[\left(a+\theta^{1 / 2}\right)^{2}+\beta \rho \sigma^{2}\right]^{2}} .
$$

Substituting equations (64), (70), and (71) into the objective function, and when the bank cooperates with a riskaverse third-party B2B platform, the optimal income of the bank under the supervision measures is

$$
E\left(U^{\prime}\right)^{*}=Q r T+\frac{\left(a+\theta^{1 / 2}\right)^{4}}{2 \beta\left[\left(a+\theta^{1 / 2}\right)^{2}+\beta \rho \sigma^{2}\right]}-V^{0}-b-d-\frac{1}{16} \theta^{2} .
$$

\section{Comparative Analysis of Incentive Contracts under Risk Neutrality and Risk Aversion}

\subsection{Effort Level $A_{E}$}

\subsubsection{Supervision Measures Are Not Considered}

Conclusion 1. When supervision measures are not taken into consideration, the optimal effort level of risk-neutral and risk-averse third-party B2B platforms in supply chain finance business is the same, that is, $A_{E}^{*}{ }^{*}=A_{E}^{*}$. It can be seen that the degree of risk aversion does not affect the optimal effort level of the B2B platform when the bank does not take supervisory measures.

Proof: $\quad$ From equations (10) and (46), we can get $A_{E}^{* *}=a \alpha / \beta=A_{E}^{*}$. The proof is complete.

\subsubsection{Considering Monitoring Measures}

Conclusion 2. When banks take supervisory measures, the best effort level of risk-neutral and risk-averse third-party $\mathrm{B} 2 \mathrm{~B}$ platforms in supply chain finance business is the same, that is, $\widehat{A}_{E}^{* *}=\widehat{A}_{E}^{*}$. It can be seen that the degree of risk aversion also does not affect the B2B platform when the bank takes supervisory measures.

Proof. From equations (28) and (64), we can get $\widehat{A}_{E}^{* *}=\left(a+\theta^{1 / 2}\right) \alpha / \beta=\widehat{A}_{E}^{*}$. The proof is complete.

\subsection{Fixed Payment $F$}

\subsubsection{Supervision Measures Are Not Considered}

Conclusion 3. When supervision measures are not considered, the optimal fixed payment given to the risk-averse third-party B2B platform by the bank is greater than the optimal fixed payment given to the risk-neutral third-party B2B platform, that is, $F^{*}>F^{* *}$. It can be seen that the risk preference of the $\mathrm{B} 2 \mathrm{~B}$ platform has an impact on the optimal fixed payment provided by the bank. When the level of risk aversion on the B2B platform increases, the fixed payment that banks need to provide in the supply chain business will also increase rapidly. When it increases to a certain extent, the fixed payment may even decline until it becomes flat. This means that banks are unwilling to pay more fixed 
payments to cooperate with B2B platforms with excessive risk aversion.
Proof. It can be obtained by equations (17) and (53):

$$
F^{* *}-F^{*}=V^{0}-\frac{a^{2}}{2 \beta}-\left[V^{0}+\frac{\beta \rho \sigma^{2} a^{4}-a^{6}}{2 \beta\left(a^{2}+\beta \rho \sigma^{2}\right)^{2}}\right]=-\frac{a^{2}\left(a^{2}+\beta \rho \sigma^{2}\right)^{2}+\beta \rho \sigma^{2} a^{4}-a^{6}}{2 \beta\left(a^{2}+\beta \rho \sigma^{2}\right)^{2}}<0,
$$

and the certificate is completed.

\subsubsection{Consider Monitoring Measures}

Conclusion 4. When the bank takes supervisory measures, the optimal fixed payment given to the risk-averse thirdparty B2B platform by the bank is greater than the optimal fixed payment given to the risk-neutral third-party B2B platform, that is, $\widehat{F}^{*}>\widehat{F}^{* *}$. It can be seen that the risk appetite of the B2B platform has an impact on the optimal fixed payment provided by the bank. It can also be concluded that when the risk aversion degree of the B2B platform increases in the early stage, the bank needs to provide in the supply chain business. The fixed payment will increase rapidly. To a certain extent, the fixed payment will even decline until it flattens out, which means that banks are unwilling to pay more fixed payments to cooperate with $\mathrm{B} 2 \mathrm{~B}$ platforms with excessive risk aversion.

Proof. It can be obtained by equations (35) and (71):

$$
\begin{aligned}
\widehat{F}^{* *}-\widehat{F}^{*} & =V^{0}-\frac{\left(a+\theta^{1 / 2}\right)^{2}}{2 \beta}-\left[V^{0}+\frac{\beta \rho \sigma^{2}\left(a+\theta^{1 / 2}\right)^{4}-\left(a+\theta^{1 / 2}\right)^{6}}{2 \beta\left[\left(a+\theta^{1 / 2}\right)^{2}+\beta \rho \sigma^{2}\right]^{2}}\right] \\
& =\frac{\left(a+\theta^{1 / 2}\right)^{2}\left[\left(a+\theta^{1 / 2}\right)^{2}+\beta \rho \sigma^{2}\right]^{2}+\beta \rho \sigma^{2}\left(a+\theta^{1 / 2}\right)^{4}-\left(a+\theta^{1 / 2}\right)^{6}}{2 \beta\left[\left(a+\theta^{1 / 2}\right)^{2}+\beta \rho \sigma^{2}\right]^{2}}<0,
\end{aligned}
$$

and the certificate is complete.

\subsection{Incentive Coefficient $\alpha$}

\subsubsection{Supervision Measures Are Not Considered}

Conclusion 5. Without considering regulatory measures, third-party B2B platforms that are averse to risk should give the best incentive coefficient. The measures given by the bank does not exceed the optimal incentive coefficient to the risk-neutral third-party B2B platform, i.e., $\alpha^{*} \leq \alpha^{* *}$. If and only if the absolute risk is measured, $\rho=0$ and $\alpha^{*}=\alpha^{* *}$. It can be seen that the risk preference of the B2B platform has an impact on the optimal incentive coefficient provided by the bank to the $\mathrm{B} 2 \mathrm{~B}$ platform. It can be known that the degree of risk aversion has a negative correlation with the incentive coefficient, i.e., the higher the degree of risk aversion, the smaller the incentive coefficient provided.

Proof. From equations (16) and (52), we can get $\alpha^{*}=a^{2} / a^{2}+\beta \rho \sigma^{2}, \beta \rho \sigma^{2} \geq 0$, so $\alpha^{*}=a^{2} / a^{2}+\beta \rho \sigma^{2} \leq 1$; when $\rho=0, \quad \alpha^{*}=a^{2} / a^{2}+\beta \rho \sigma^{2}=1=\alpha^{* *}$. The proof is complete.

\subsubsection{Considering Monitoring Measures}

Conclusion 6. When banks take supervisory measures, the optimal incentive coefficient given to the risk-averse thirdparty B2B platform by the bank does not exceed the optimal incentive coefficient given to the risk-neutral third-party B2B platform, that is $\widehat{\alpha}^{*} \leq \widehat{\alpha}^{* *}$, if and only if the absolute risk when measuring $\rho=0, \widehat{\alpha}^{*}=\widehat{\alpha}^{* *}$. It can be seen that the risk preference of the $\mathrm{B} 2 \mathrm{~B}$ platform affects the optimal incentive coefficient provided by the bank to the $\mathrm{B} 2 \mathrm{~B}$ platform. It can be known that the degree of risk aversion and the incentive coefficient are negatively correlated, that is, the higher the degree of risk aversion, the smaller the incentive coefficient provided.

Proof. From equations (34) and (70), we can get $\widehat{\alpha}^{*}=$ $\left(a+\theta^{1 / 2}\right)^{2} /\left(a+\theta^{1 / 2}\right)^{2}+\beta \rho \sigma^{2}, \quad \beta \rho \sigma^{2} \geq 0, \quad$ so $\quad \widehat{\alpha}^{*}=(a+$ $\left.\theta^{1 / 2}\right)^{2} /\left(a+\theta^{1 / 2}\right)^{2}+\beta \rho \sigma^{2} \leq 1$; when $\rho=0$, $\widehat{\alpha}^{*}=\left(a+\theta^{1 / 2}\right)^{2}$ $/\left(a+\theta^{1 / 2}\right)^{2}+\beta \rho \sigma^{2}=1=\widehat{\alpha}^{* *}$. The proof is complete.

\subsection{Bank Income $E(U)$}

\subsubsection{Not Considering Supervision Measures}

Conclusion 7. When supervision measures are not taken into consideration, the optimal benefit obtained by 
cooperation with a risk-neutral B2B platform is greater than the optimal benefit obtained by cooperation with a riskaverse B2B platform, that is, $E(U)^{* *}>E(U)^{*}$. Therefore, when choosing a third-party B2B platform for cooperation, banks should conduct investigations and cooperate with third-party B2B platforms with a low degree of risk aversion.
At the same time, B2B platforms should also adjust their internal structure, accelerate transformation, and communicate with banks better.

Proof. It can be obtained by equations (18) and (54):

$$
E(U)^{* *}-E(U)^{*}=Q r T+\frac{a^{2}}{2 \beta}-V^{0}-b-d-\left[Q r T+\frac{a^{4}}{2 \beta\left(a^{2}+\beta \rho \sigma^{2}\right)}-b-d-V^{0}\right]=\frac{a^{2} \beta \rho \sigma^{2}}{2 \beta\left(a^{2}+\beta \rho \sigma^{2}\right)}>0
$$

And the certificate is complete.

\subsubsection{Considering Monitoring Measures}

Conclusion 8. When the bank adopts supervisory measures, the optimal return obtained by the bank and the risk-neutral enterprise is greater than the optimal return obtained by the risk-averse enterprise, that is, $E\left(U^{\prime}\right)^{* *}>E\left(U^{\prime}\right)^{*}$. Therefore, when choosing a third-party B2B platform for cooperation, banks should conduct investigations and cooperate with third-party B2B platforms with low-risk aversion. At the same time, B2B platforms should also adjust their internal structure, accelerate transformation, and cooperate with banks better.

Proof. It can be obtained by equations (36) and (72):

$$
\begin{aligned}
E\left(U^{\prime}\right)^{* *}-E\left(U^{\prime}\right)^{*} & =\operatorname{QrT}+\frac{\left(a+\theta^{1 / 2}\right)^{2}}{2 \beta}-V^{0}-b-d-\frac{1}{16} \theta^{2}-\left\{\operatorname{QrT}+\frac{\left(a+\theta^{1 / 2}\right)^{4}}{2 \beta\left[\left(a+\theta^{1 / 2}\right)^{2}+\beta \rho \sigma^{2}\right]}-b-d-V^{0}-\frac{1}{16} \theta^{2}\right\} \\
& =\frac{\left(a+\theta^{1 / 2}\right)^{2}}{2 \beta}-\frac{\left(a+\theta^{1 / 2}\right)^{4}}{2 \beta\left[\left(a+\theta^{1 / 2}\right)^{2}+\beta \rho \sigma^{2}\right]} \\
& =\frac{\left(a+\theta^{1 / 2}\right)^{2}\left[\left(a+\theta^{1 / 2}\right)^{2}+\beta \rho \sigma^{2}\right]-\left(a+\theta^{1 / 2}\right)^{4}}{2 \beta\left[\left(a+\theta^{1 / 2}\right)^{2}+\beta \rho \sigma^{2}\right]}>0 .
\end{aligned}
$$

And the certificate is complete.

\section{Numerical Simulation}

6.1. Parameter Assignment. To explain the actual operability of the results of this paper and the expected utility of the bank along with the third-party B2B platform to recover losses $a$, the cost coefficient $\beta$, the absolute risk aversion measurement $\rho$, and the change law of bank supervision $\theta$, a corresponding numerical analysis is given:

(2) Assuming that the average natural loss of the pledge during the loan cycle is 150 , that is, $b=150$, and the loss is $d=200$ due to the third-party B2B platform's lack of effort

(3) Assuming that the retained utility of the third-party B2B platform is $V^{0}=80$

(4) Assuming that $\varepsilon \sim N(0,900)$ is in a normal distribution, namely, $\sigma^{2}=900$
Then, we have the following:

(1) When a bank cooperates with a risk-averse thirdparty B2B platform, the optimal expected utility of the bank without taking supervision measures is simplified to

$$
E(U)^{*}=170+\frac{a^{4}}{2 \beta\left(a^{2}+900 \beta \rho\right)} .
$$

(2) When the bank cooperates with a risk-neutral thirdparty B2B platform, the optimal expected utility of the bank is simplified to

$$
E(U)^{* *}=170+\frac{a^{2}}{2 \beta}
$$

(3) When a bank cooperates with a risk-averse thirdparty B2B platform, the optimal expected utility of the bank is simplified as follows: 


$$
E\left(U^{\prime}\right)^{*}=170+\frac{\left(a+\theta^{1 / 2}\right)^{4}}{2 \beta\left[\left(a+\theta^{1 / 2}\right)^{2}+900 \beta \rho\right]}-\frac{1}{16} \theta^{2} .
$$

(4) When a bank cooperates with a risk-neutral thirdparty B2B platform, the optimal expected utility of the bank is simplified as follows:

$$
E\left(U^{\prime}\right)^{*}=170+\frac{\left(a+\theta^{1 / 2}\right)^{4}}{2 \beta}-\frac{1}{16} \theta^{2} .
$$

\subsection{Numerical Analysis}

6.2.1. Not Considering the Impact of Relevant Parameters on Bank Utility under Supervision Measures. In the following figures, $E(U)^{*}$ represents the change curve of the expected utility function of the bank when the bank cooperates with the risk-averse third-party B2B platform without supervisory measures and $E(U)^{* *}$ represents the change curve of the expected utility function of the bank when the bank cooperates with a risk-neutral third-party B2B platform without supervision measures (Figures 1-3).

(1) Let $\beta=0.2, \rho=4$; at this time, the expected income of the bank changes with the third-party B2B platform's ability to recover losses $a$. The impact of $a$ on expected bank utility is shown in Figure 1.

It can be seen from Figure 1 that the two curves of $E(U)^{*}$ and $E(U)^{* *}$ are monotonically increasing. The growth rate increases, which shows whether the bank cooperates with a risk-averse third-party B2B platform or a risk-neutral third-party B2B platform. The greater the third-party B2B platform's ability to recover losses, the higher the expected utility of the bank. The expected utility of the bank increases exponentially as the third-party $\mathrm{B} 2 \mathrm{~B}$ platform recovers losses.

It can also be seen from Figure 1 that the curve of $E(U)^{* *}$ is always on the top of $E(U)^{*}$. For the same ability $a=30$, the income obtained by the cooperation between the bank and the risk-averse thirdparty $\mathrm{B} 2 \mathrm{~B}$ platform and the income obtained by the cooperation between the bank and the risk-neutral third-party B2B platform is 1420 and 2420 , respectively. The results show that the benefits obtained by banks from cooperating with risk-neutral companies are greater than those obtained by riskaverse companies.

(2) Let $a=30$ and $\rho=4$; at this time, the bank's expected income changes with the cost coefficient $\beta$ of the third-party $\mathrm{B} 2 \mathrm{~B}$ platform. The impact of $\beta$ on expected bank utility is shown in Figure 2 .

It can be seen from Figure 2 that the two curves of $E(U)^{*}$ and $E(U)^{* *}$ are monotonically decreasing. The deceleration is on the rise, indicating whether

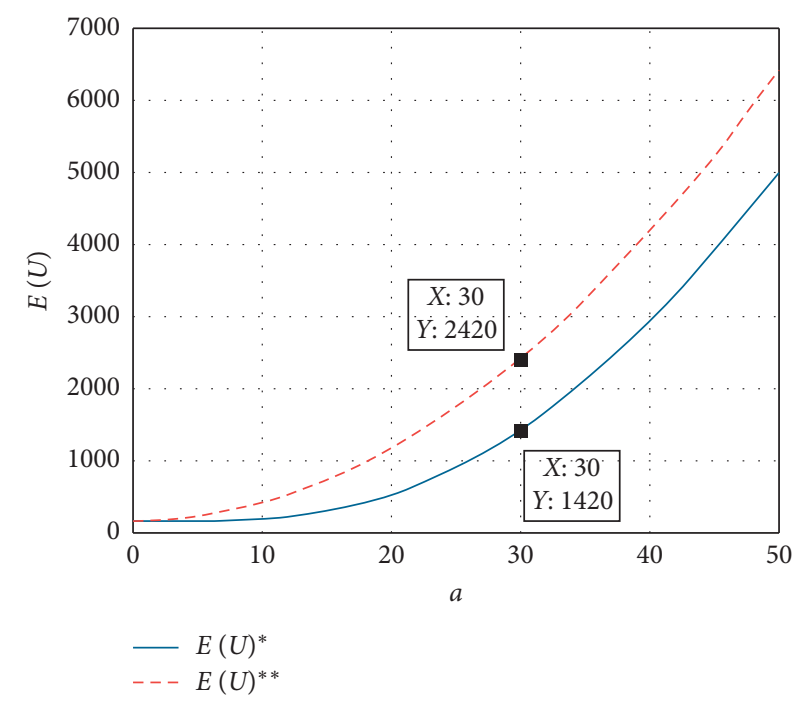

FIgURE 1: The impact of $a$ on expected bank utility.

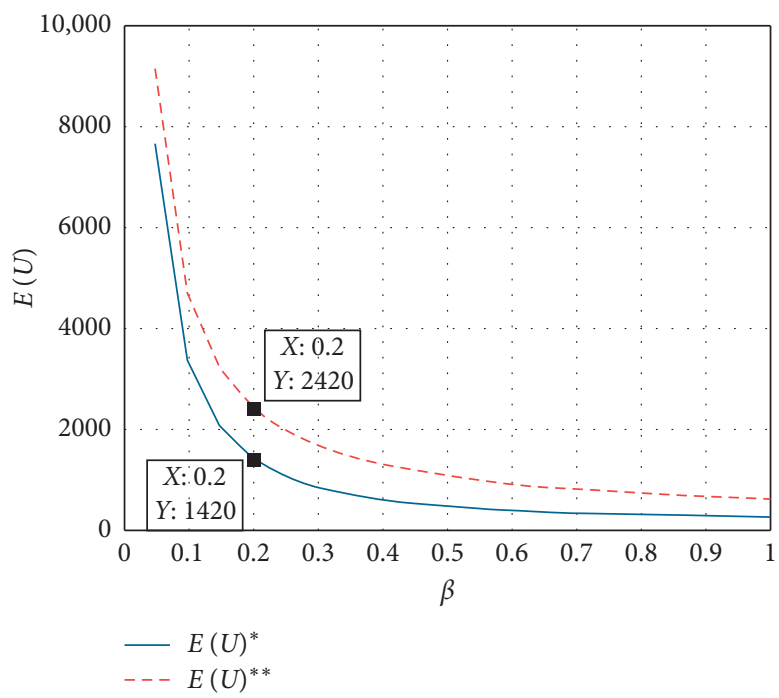

FIgURE 2: The impact of $\beta$ on expected bank utility.

the bank cooperates with a risk-averse third-party B2B platform or a risk-neutral third-party B2B platform. The lower the cost coefficient of the third party B2B platform, the higher the expected utility of the bank. The bank's expected utility decreases exponentially as the cost coefficient $\beta$ of the third-party B2B platform increases.

It can also be seen from Figure 2 that $E(U)^{* *}$ is always on the top of $E(U)^{*}$. For the same cost coefficient $\beta=0.2$, the income obtained by the cooperation between the bank and the risk-averse thirdparty $\mathrm{B} 2 \mathrm{~B}$ platform and the income obtained by the cooperation between the bank and the risk-neutral third-party B2B platform is 1420 and 2420 , respectively. This shows that banks' benefits from cooperating with risk-neutral companies are greater than those from risk-averse companies, which is consistent with conclusion 7 . 


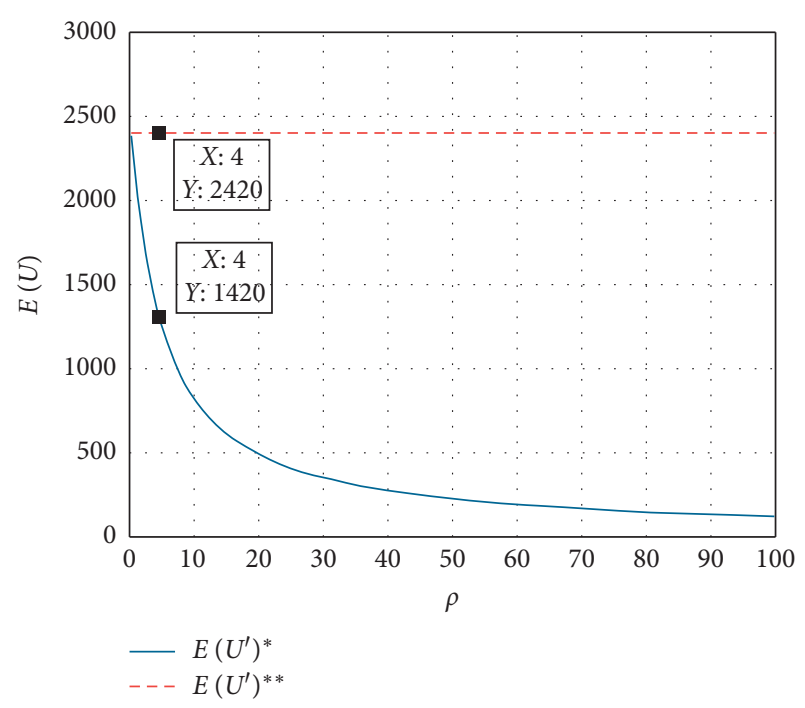

FIgURE 3: The impact of $\rho$ on expected bank utility.

(3) Let $a=30, \beta=0.2$; at this time, the bank's expected return changes with the absolute risk measurement $\rho$ of the third-party B2B platform. The impact of $\rho$ on expected bank utility is shown in Figure 3 .

It can be seen from Figure 3 that the curve $E(U)^{*}$ is monotonously decreasing. The deceleration shows an upward trend, which indicates that when banks cooperate with risk-averse third-party $\mathrm{B} 2 \mathrm{~B}$ platforms, the greater the absolute risk measurement $\rho$ of the third-party B2B platform, i.e., the higher degree of risk-aversion of the third-party $\mathrm{B} 2 \mathrm{~B}$ platform, the lower the bank's expected utility, and the expected utility of the bank decreases exponentially as the absolute risk measurement $\rho$ of the third-party B2B platform increases.

It can also be seen from Figure 3 that $\rho=0 E(U)^{* *}$ is in a straight line and is always at the top of $E(U)^{*}$. It indicates that the benefits obtained by the cooperation between banks and risk-neutral enterprises are greater than those obtained by risk-averse enterprises, which is consistent with conclusion 7.

\subsubsection{Considering the Impact of Relevant Parameters on Bank} Utility under Supervision Measures. In the following figures, $E\left(U^{\prime}\right)^{*}$ shows the change curve of the expected utility function of the bank when the bank cooperates with the riskaverse third-party B2B platform. $E\left(U^{\prime}\right)^{* *}$ shows the curve of the expected utility function of the bank when the bank cooperates with the risk-neutral third-party B2B platform with the supervisory measures being taken (Figures 4-7).

(1) Let $\beta=0.2, \rho=4, \theta=36$; the bank's expected income changes with the third-party B2B platform's ability to recover losses $a$. The impact of $a$ on expected bank utility is shown in Figure 4.

It can be seen from Figure 4 that the two curves of $E\left(U^{\prime}\right)^{*}$ and $E\left(U^{\prime}\right)^{* *}$ are similar to the shape of banks without supervision, and they are

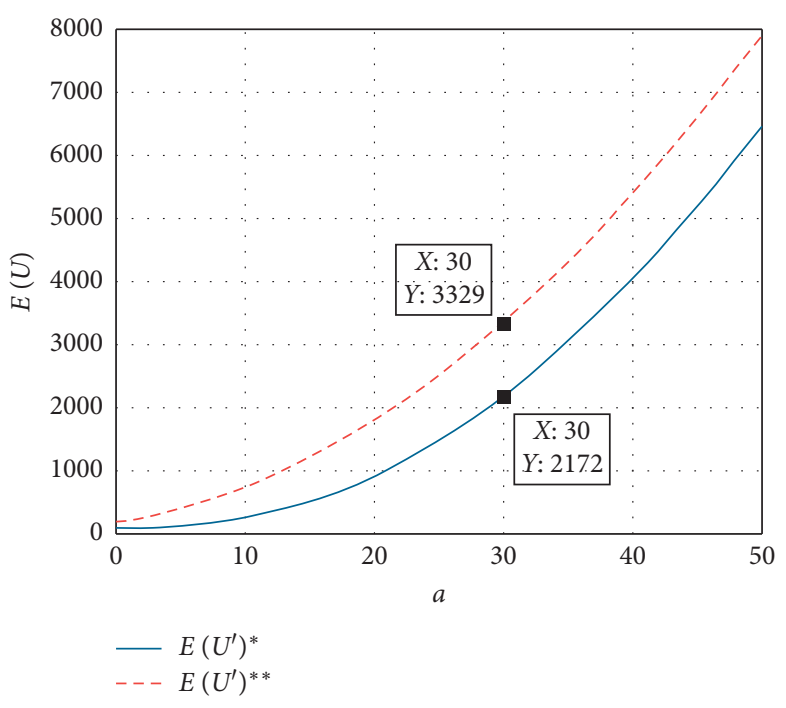

FIgURE 4: The impact of $a$ on expected bank utility.

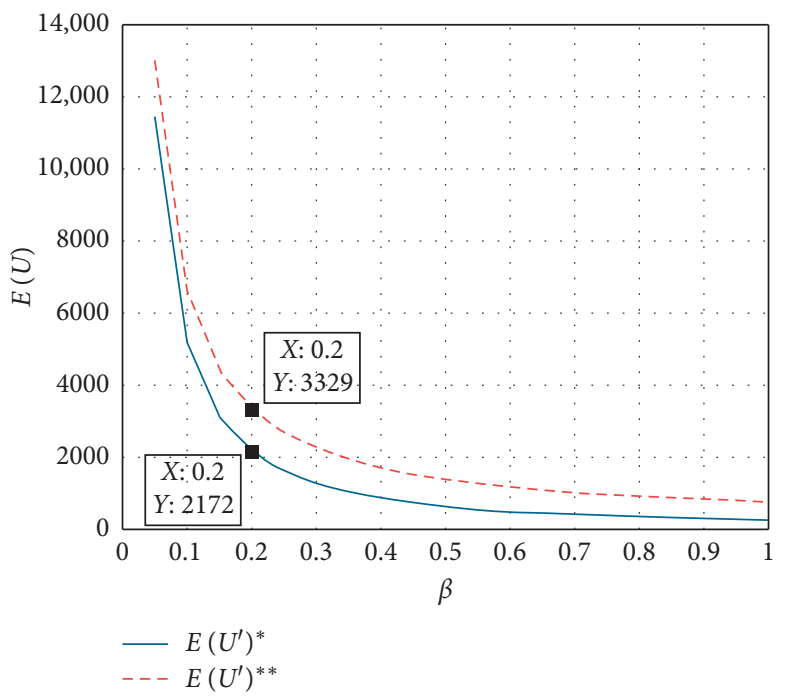

FIgURE 5: The impact of $\beta$ on expected bank utility.

monotonically increasing. This shows that regardless of whether the bank takes supervision measures, the greater the third-party B2B platform's ability to recover losses, the higher the expected utility of the bank. Similarly, when banks take supervisory measures, $E\left(U^{\prime}\right)^{* *}$ is always above $E\left(U^{\prime}\right)^{*}$. For the same ability $a=30$, the income obtained by the cooperation between the bank and the risk-averse third-party B2B platform and the income obtained by the cooperation between the bank and the riskneutral third-party B2B platform is, respectively, 2172 and 3329. This shows that banks' benefits from cooperating with risk-neutral companies are greater than those from risk-averse companies, which is consistent with conclusion 8 .

(2) Let $a=30, \rho=4$, and $\theta=36$; the bank's expected income changes with the cost coefficient $\beta$ of the 
third-party $\mathrm{B} 2 \mathrm{~B}$ platform. The impact of $\beta$ on expected bank utility is shown in Figure 5 .

It can be seen from Figure 5 that the two curves of $E\left(U^{\prime}\right)^{*}$ and $E\left(U^{\prime}\right)^{* *}$ are similar to the shape of banks without supervision, and they are monotonically decreasing. This shows that regardless of whether the bank takes supervision measures, the lower the third-party B2B platform's cost coefficient, the higher the bank's expected utility. Similarly, in the case of banks taking supervisory measures, the curve $E\left(U^{\prime}\right)^{* *}$ is always above the curve $E\left(U^{\prime}\right)^{*}$. For the same cost coefficient $\beta=0.2$, the income obtained by the cooperation between the bank and the risk-averse third-party $\mathrm{B} 2 \mathrm{~B}$ platform and the income obtained by the cooperation between the bank and the risk-neutral third-party B2B platform is, respectively, 2172 and 3329 . This shows that banks' benefits from cooperating with risk-neutral companies are greater than those from risk-averse companies, which is consistent with conclusion 8 .

(3) Let $a=30, \beta=0.2$, and $\theta=36$; the bank's expected return changes with the absolute risk measurement of the third-party B2B platform. The impact of $\rho$ on expected bank utility is shown in Figure 6.

It can be seen from Figure 6 that the curve $E\left(U^{\prime}\right)^{*}$ is similar to the shape of the bank without supervision, and it is monotonically decreasing. This shows that regardless of whether the bank takes supervision measures, the lower the third-party B2B platform's cost coefficient, the higher the expected utility of the bank. Similarly, in the case of banks taking supervisory measures, the straight line $E\left(U^{\prime}\right)^{* *}$ is always above the curve $E\left(U^{\prime}\right)^{*}$, indicating that the bank's benefits from cooperation with risk-neutral companies are greater than those from risk-averse companies consistent with Conclusion 8 .

(4) Let $a=30, \beta=0.2$, and $\rho=4$; the bank's expected return changes with the intensity of bank supervision $\theta$. The impact of $\theta$ on expected bank utility is shown in Figure 7.

It can be seen from Figure 7 that the two curves $E(U)^{*}$ and $E(U)^{* *}$ are concave functions that increase first and then decrease, which indicates whether banks cooperate with risk-averse third-party $\mathrm{B} 2 \mathrm{~B}$ platforms or risk-neutral thirdparty B2B platforms. The expected utility of the bank increases at the initial stage when banks are increasing supervision intensity. When the intensity of supervision continues to increase to a certain level, the expected utility of ebank will change. When it increases to a certain level, the bank's expected utility begins to be negative, which conforms to the law of diminishing marginal returns.

It can also be seen from Figure 7 that this curve $E(U)^{* *}$ is always at the top of $E(U)^{*}$. For the same supervision strength $\theta=36$, the income obtained by the cooperation between the bank and the risk-averse third-party B2B platform and the income obtained by the cooperation between the bank and the risk-neutral third-party B2B

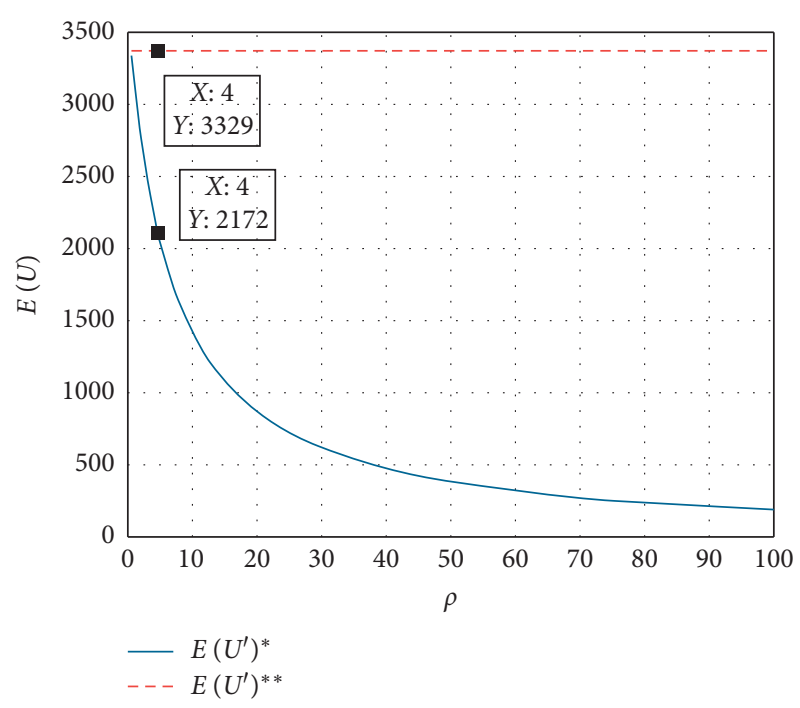

FIgURE 6: The impact of $\rho$ on expected bank utility.

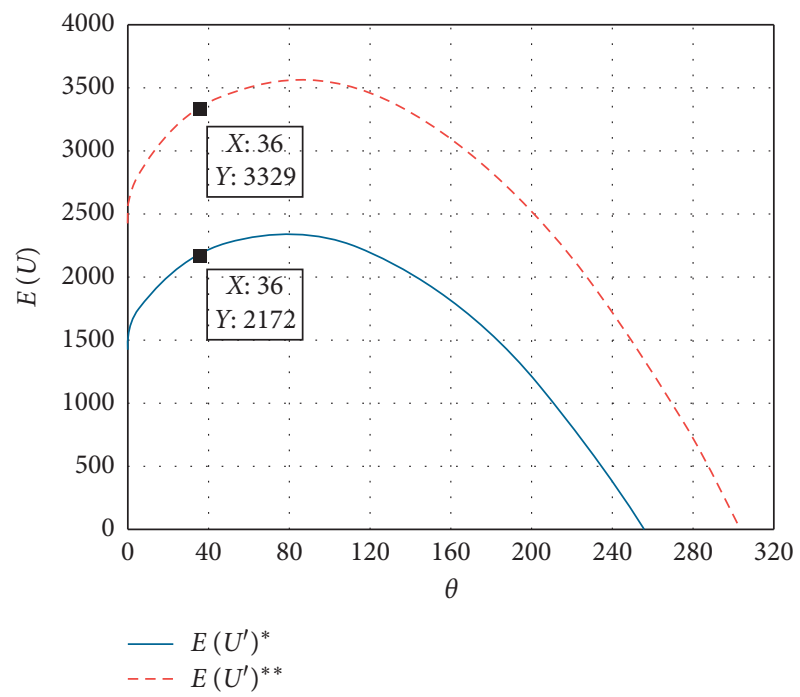

FIgURE 7: The impact of $\theta$ on expected bank utility.

platform is, respectively, 2172 and 3329. It shows that banks' benefits from cooperating with risk-neutral companies are greater than those from risk-averse companies, which is consistent with conclusion 8 .

6.2.3. The Impact of Supervisory Measures on Bank Utility in Four Situations. Let $a=30, \beta=0.2, \rho=4$; the bank's expected return changes with bank supervision intensity $\theta$. Figure 8 compares the four situations in which banks and risk-averse and risk-neutral third-party B2B platforms cooperate with and without supervisory measures and analyzes the impact of supervisory measures on banks' expected utility. $E(U)^{*}$ $E(U)^{* *}$ and $E\left(U^{\prime}\right)^{* *}$ have the same meaning as before.

It can be seen from Figure 8 that since $\theta=0, E(U)^{*}$ and $E(U)^{* *}$ have a straight-line shape, and the two curves increase first and then decrease, conforming to the law of diminishing marginal returns; the straight line $E(U)^{* *}$ is 


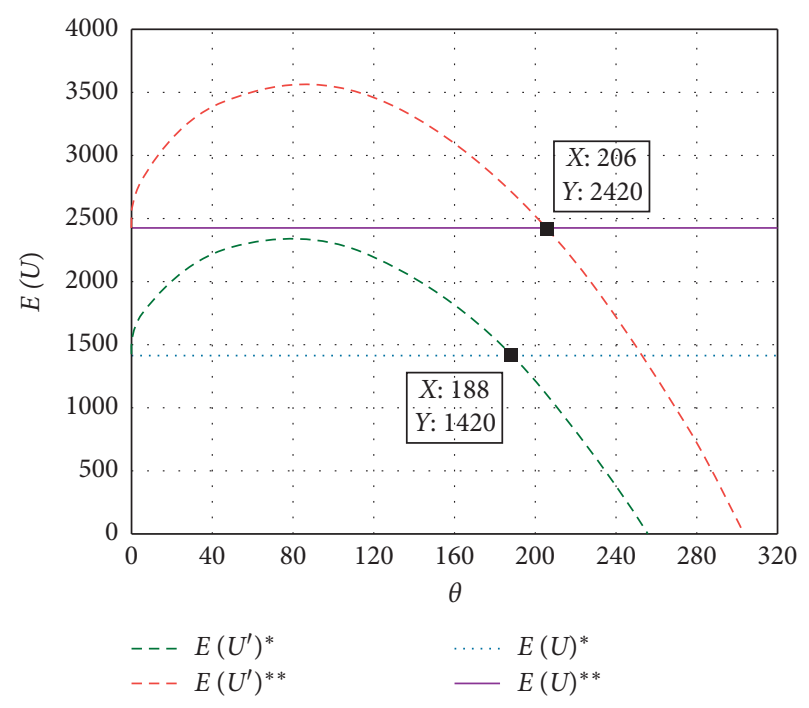

FIgURE 8: The impact of $\theta$ on expected bank utility.

always above the straight line $E(U)^{*}$, and the curve $E\left(U^{\prime}\right)^{* *}$ is always above the curve $E\left(U^{\prime}\right)^{*}$, indicating whether supervision measures are taken or not, the expected utility obtained by the cooperation of the bank and the riskneutral third-party B2B platform is higher than the expected utility obtained by the cooperation with the risk-averse third-party B2B platform, which is consistent with conclusions 7 and 8 .

It can also be seen from Figure 8 that when $\theta \leq 188$, the curve $E\left(U^{\prime}\right)^{*}$ is above the straight line $E(U)^{*}$. When $\theta>188$, the curve $E\left(U^{\prime}\right)^{*}$ is below the straight line $E(U)^{*}$, when $\theta \leq 206$, the curve $E\left(U^{\prime}\right)^{* *}$ is above the straight line $E(U)^{* *}$, and when $\theta>206$, the curve $E\left(U^{\prime}\right)^{* *}$ is below the straight line $E(U)^{* *}$. Therefore, when banks cooperate with risk-averse third-party $\mathrm{B} 2 \mathrm{~B}$ platforms, $\theta \leq 188$, the increase in bank utility due to supervisory measures' adoption will be higher than the supervision cost. At this time, the bank will choose to take supervisory measures; otherwise, it will not take supervisory measures; when the bank cooperates with a risk-neutral third-party B2B platform, $\theta \leq 206$, the increase in bank utility due to the adoption of supervisory measures will be higher than the cost of supervision. At this time, the bank will choose to take supervisory measures; otherwise, it will not take supervisory measures.

\section{Conclusions}

This paper analyzes the two perspectives of cooperation between the bank and the risk-neutral third-party B2B platform and the cooperation between the bank and the riskaverse third-party B2B platform. It compares the level of benefits brought to the bank by the two third-party B2B platforms with risk attitudes. Numerical simulation analysis with MATLAB software verifies the model's accuracy and provides some suggestions for banks to make a better choice of a third-party B2B platform for cooperation.

Therefore, based on the above analysis, the main conclusions of this paper are
(1) Whether the bank takes supervision measures or not, the optimal expected return obtained when the bank cooperates with a risk-neutral third-party B2B platform is always greater than the optimal expected return obtained when the bank cooperates with a risk-averse third-party B2B platform. The degree of risk aversion of the tripartite $\mathrm{B} 2 \mathrm{~B}$ platform is negatively related to the bank's expected return.

(2) Whether the bank cooperates with a risk-neutral or risk-averse third-party B2B platform, the bank's expected utility increases in the initial stage of increasing supervision. When the supervision continues to increase beyond a certain value, the bank's expected utility begins to decrease. When the supervision increases to a certain extent, the bank's expected utility will become negative, which conforms to the law of diminishing marginal returns.

(3) The third-party B2B platform's ability to recover losses is positively correlated with the bank's expected utility, and the cost coefficient of the thirdparty $\mathrm{B} 2 \mathrm{~B}$ platform is negatively correlated with the bank's expected utility.

(4) When banks cooperate with risk-neutral and riskaverse third-party B2B platforms, banks' supervisory measures will increase the level of effort of the $B 2 B$ platform. At this time, banks' fixed payments to B2B platforms are less than those without supervisory measures. When working with a risk-neutral thirdparty B2B platform, the incentive coefficient is the same as when no supervision measures are taken. Still, when working with a risk-averse third-party B2B platform, the incentive coefficient is higher when no supervision measures are taken.

(5) Whether or not the bank takes supervisory measures, risk appetite does not affect the optimal effort level of the B2B platform. The risk appetite of the B2B platform has an impact on the optimal fixed payment provided by the bank, and it also has an impact on the optimal incentive coefficient of the B2B platform provided by the bank. In addition, the degree of risk aversion has a negative correlation with the incentive coefficient.

This paper uses electronic warehouse receipt pledge financing as an example to analyze the possible moral hazards of the $\mathrm{B} 2 \mathrm{~B}$ platform in the process of the bank entrusting credit to the third-party $\mathrm{B} 2 \mathrm{~B}$ platform. It uses the principalagent theory to study the bank's incentive strategy selection for the third-party B2B platform under entrusted credit. It is of great practical significance to ease the problem of SME financing difficulties. This article mainly studies the moral hazard problem of hidden behavior and does not involve hidden information's moral hazard problem. Therefore, an information hiding model can be established in the future to study the moral hazard problem of hidden information. In addition, a key conclusion drawn in this article is that a key factor for investigating whether banks will take supervisory measures is the cost of supervision. Therefore, in the future, 
we can combine the specific online supply chain finance business model to conduct an in-depth analysis of the supervision cost function to obtain the bank's optimal supervision strength.

\section{Data Availability}

The datasets used and/or analyzed during the current study are available from the corresponding author on reasonable request.

\section{Conflicts of Interest}

The authors declare that they have no conflicts of interest.

\section{Acknowledgments}

The study was supported by the National Natural Science Foundation of China (Grant no. 71671030) and Scientific Research Fund Project of Liaoning Provincial Department of Education, China (Grant no. JFW201915401).

\section{References}

[1] J. Shi, J. E. Guo, S. Wang, and Z. Wang, "Credit risk evaluation of online supply chain finance based on third-party B2B E-commerce platform: an exploratory research based on China's practice," International Journal of $u$ - and e-Service, Science and Technology, vol. 8, no. 5, pp. 93-104, 2015.

[2] V. Sadlovska, "Supply chain finance for emerging markets," Supply Chain Brain, vol. 16, no. 1, pp. 7-28, 2012.

[3] X.-H. Sun, X.-J. Chu, and Z.-D. Wu, "Incentive regulation of banks on third party logistics enterprises in principal-agentbased inventory financing," Advances in Manufacturing, vol. 2, no. 2, pp. 150-157, 2014.

[4] B. Li, P. Chen, Q. Li, and W. Wang, "Dual-channel supply chain pricing decisions with a risk-averse retailer," International Journal of Production Research, vol. 52, no. 23, pp. 7132-7147, 2014.

[5] T. Vetter, J. Reinhardt, M. Flörke et al., "Evaluation of sources of uncertainty in projected hydrological changes under climate change in 12 large-scale river basins," Climatic Change, vol. 141, no. 3, pp. 419-433, 2017.

[6] Y. J. Zhou, Q. Chen, X. H. Chen et al., "Stackelberg game of buyback policy in supply chain with a risk-averse retailer and a risk-averse supplier based on CVaR," Plos One, vol. 9, no. 9, pp. 71-76, 2014.

[7] J. A. C. de Goeij, A. T. C. Onstein, and M. A. Steeman, "Impediments to the adoption of reverse factoring for logistics service providers," Logistics and Supply Chain Innovation, pp. 261-277, Springer, Berlin, Switzerland, 2016.

[8] J. S. Dai and W. D. Meng, "A risk-averse newsvendor model under marketing-dependency and price-dependency," International Journal of Production Economics, vol. 160, pp. 220-229, 2014.

[9] G. Aust, "Vertical cooperative advertising and pricing decisions in a manufacturer-retailer supply chain: a game-theoretic approach," Vertical Cooperative Advertising in Supply Chain Management, Springer, Berlin, Switzerland, 2015.

[10] X. Q. Xu and M. A. Zhonghua, "The supply chain financing decision of third-party logistics participation considering supplier competition," China Population Resources \& Environment, vol. 12, 2017.
[11] M. B. Wessman, "Purchase money inventory financing:The case for limited cross-collateralization," The Ohio State Law Journal, vol. 51, pp. 1283-1447, 2017.

[12] M. Lamoureux, "A supply chain finance prime," Supply Chain Finance, vol. 4, no. 3, pp. 34-48, 2007.

[13] E. Hofmann, "Inventory financing in supply chains," International Journal of Physical Distribution \& Logistics Management, vol. 39, no. 9, pp. 716-740, 2009.

[14] L. Klapper, The Role of Reverse Factoring in Supplier Financing of Small and Medium Sized Enterprises, World Bank, Washington, DC, USA, 2004.

[15] H.-C. Pfohl and M. Gomm, "Supply chain finance: optimizing financial flows in supply chains," Logistics Research, vol. 1, pp. 149-161, 2009.

[16] S. Chopra and P. Meindl, Supply Chain Management: Strategy, Planning \& Operations, Pearson Prentice-Hall, Upper Saddle River, NY, USA, 2008.

[17] D. Yang, T. Xiao, and H. Shen, "Pricing, service level and lot size decisions of a supply chain with risk-averse retailers: implications to practitioners," Production Planning \& Control, vol. 20, no. 4, pp. 320-331, 2009.

[18] B. Dyckman, "Supply chain finance: risk mitigation and revenue growth," Journal of Corporate Treasury Management, vol. 4, no. 2, pp. 168-173, 2011.

[19] G. Kong, S. Rajagopalan, and H. Zhang, "Revenue sharing and information leakage in a supply chain," Management Science, vol. 59, no. 3, pp. 556-572, 2013.

[20] W. Barnett and Jeong, "Financial-firm production of monetary services: a generalized symmetric Barnett variableprofit-function approach," Journal of Business \& Economic Statistics, vol. 12, no. 1, pp. 33-46, 2014. 